\title{
Diagnóstico da gestão de lodo de estação de tratamento de água em Mato Grosso do Sul
}

\author{
Diagnosis of sludge management in Mato Grosso do Sul's water \\ treatment plants
}

\section{Diagnostic de gestion de boue des stations de traitement de l'eau en Mato Grosso do Sul}

\author{
Diagnóstico de gestión de lodos de estacíon de tratamiento de agua en Mato \\ Grosso do Sul
}

\author{
Isadora Yule Queiroz de Oliveira* \\ Odilar Costa Rondon*
}

\begin{abstract}
Recebido em 16/05/2016; revisado e aprovado em 22/06/2016; aceito em 10/08/2016
DOI: http:/ / dx.doi.org/10.20435/1984-042X-2016-v.17-n.4(11)
\end{abstract}

\begin{abstract}
Resumo: O objetivo deste trabalho foi diagnosticar a gestão do lodo gerado durante o processo de tratamento de água, a partir de dados levantados sobre o sistema operacional de estações de tratamento de água (ETAs) avaliadas em Mato Grosso do Sul para analisar o volume e o gerenciamento (transformação/reaproveitamento e/ou disposição final) do lodo de ETA. Sendo o lodo um resíduo - e não um rejeito, conforme com a Lei 12.305/2010 (BRASIL, 2010) - ele deveria ter tratamento ecologicamente adequado optando-se por redução, reuso e reciclagem.
\end{abstract}

Palavras-chave: estação de tratamento de água; produção de lodo; quantificação de lodo.

Abstract: The objective of this paper was to diagnose the sludge management generated during the water treatment process, from data collected on the water treatment's operating system evaluated in Mato Grosso do Sul to analyze the sludge's volume and management (processing/recycling and/ or disposal). The sludge is a residue - not a waste, according to the Law 12.305/2010 (BRASIL, 2010) - it should have ecologically appropriate treatment choosing the reduction, reuse and recycling. Key words: water treatment plant; sludge production; sludge quantification.

Résumé: L'objectif de cet article était de diagnostiquer la gestion des boues générées pendant le processus de traitement de l'eau, a partir des données recueillies sur le système d'exploitation de traitement de l'eau évalué dans le Mato Grosso do Sul pour analyser le volume de boues et de gestion (traitement/recyclage et/ou élimination). La boue est un résidu - pas un déchet, conformément à la loi 12.305/2010 (BRASIL, 2010) - il devrait avoir un traitement écologiquement appropriée choisissant la réduction, la réutilisation et le recyclage.

Móts-clés: station de traitement de l'eau; production de boues; quantification de boues.

Resumen: El objetivo del trabajo fue diagnosticar la gestión de los lodos generados durante el proceso de tratamiento de agua, a partir de datos recogidos en el sistema operativo de las plantas de tratamiento de agua evaluados en Mato Grosso do Sul para analizar el volumen y la gestión (tratamiento/reciclaje y/o eliminación) de lodo. El lodo es un residuo - no es un desecho, de acuerdo con la Ley 12.305/2010 (BRASIL, 2010) - él debe tener el tratamiento ecológicamente adecuada elección de la reducción, la reutilización y el reciclado.

Palabras clave: estación de tratamiento de agua; producción de lodos; cuantificación de lodos.

\section{INTRODUÇÃO}

A água está centralmente relacionada ao desenvolvimento social, econômico e ambiental entre todos os países. Segundo o Relatório Mundial das Nações
Unidas sobre o Desenvolvimento de Recursos Hídricos - Água para um mundo sustentável 2015, divulgado em março de 2015, o consumo de água cresceu duas vezes mais que a população e a estimativa é que a demanda aumente $55 \%$ até 2050 ,

\footnotetext{
* Universidade Federal de Mato Grosso do Sul, Campo Grande, Mato Grosso do Sul, Brasil.
} 
além de prever que a população mundial chegará a 9,6 bilhões no mesmo ano.

Segundo o Relatório Mundial da Organização das Nações Unidas (ONU, 2015), a crescente busca por água potável é confrontada pelo acréscimo de quantidade de resíduos nas Estações de Tratamento de Água (ETAs). Por consequência, é preciso empregar tecnologias que permitam a reciclagem e a exploração desses resíduos. O Brasil possui uma população de aproximadamente 204 milhões de habitantes (IBGE, 2010) e, consequentemente, alto consumo de água potável e construção de ETAs.

É preciso ver as concessionárias de tratamento e distribuição de água como indústrias, seu papel é converter água bruta em água potável por meio de produtos químicos e processos conforme a legislação e correlacionar ao fato de que todo processo industrial gera resíduos. $\mathrm{O}$ despejo de efluentes da água de descarga dos decantadores e de lavagem de filtros, que contém grande quantidade de sólidos e compostos químicos nos cursos d'água é o maior problema de poluição em uma ETA.

O estudo de Assis (2014) conclui que o lançamento in natura - sem tratamento prévio - do lodo nos corpos hídricos eleva a concentração de sólidos totais na água, a ETA estudada pode acrescentar 37 toneladas de sólidos totais a cada 60 dias no córrego analisado. Estudos realizados por Achon et al. (2005) constataram que o lodo descartado in natura na ETA de São Carlos, SP, possuía alta concentração de alumínio e ferro e comprometeu a camada bentônica do córrego em que foi despejado, além aumentar a turbidez e a aumentar a demanda química de oxigênio.

O gerenciamento ambiental de uma ETA é importante para garantir a qualidade do produto final e diminuir a geração de resíduos. Segundo Dijkema et al. (2000 apud PORRAS, 2007), o conceito de resíduo vem se reinterpretando como uma "matéria-prima de um novo processo, ou seja, um produto é considerado resíduo quando não tenha sido usado em todo seu potencial".

No Brasil, o tratamento da água é feito através do processo convencional de ciclo completo tendo as fases de: captação, coagulação, floculação, decantação, filtração e cloração. A consequência desses processos é a geração de subprodutos, os resíduos sólidos conhecidos como o lodo: uma torta densa e viscosa, que é um grande problema ambiental caso não seja destinado corretamente. Tomando por base que a geração de resíduo de ETA é de 5\% sobre a produção de água por dia (ANDREOLI, 2001), são fundamentais os estudos sobre avaliação de aproveitamento do lodo e suas potencialidades.

O lodo é o aglomerado de substâncias retiradas da água durante o processo de tratamento. É referente ao tipo de coagulante utilizado no processo de tratamento, em razão de que diferentes locais de retirada de água bruta garantem propriedades distintas e, logo, diferentes dosagens de coagulantes. Quanto mais deteriorada for a água bruta, maior quantidade de produtos adicionados no tratamento.

O Brasil produz 4 milhões de toneladas por ano de lodo de ETA (SILVA, 2011). O Estado de São Paulo, conforme os dados de Cosin et al. (2004), gera 30 mil ton./ano. A cada mês no Paraná, são produzidas 4 mil toneladas de matéria seca de lodo. Conforme HOPPEN et al. (2005), uma ETA convencional com capacidade de tratamento de $24001 / \mathrm{s}$ consegue produzir 1,8t/dia de lodo. $\mathrm{O}$ grande volume de lodo gerado necessita de um gerenciamento e disposição final adequada ambientalmente.

De acordo com Achon (2008), Andrade (2014), Katayama (2012) e Ribeiro (2003), a grande maioria das ETAs brasileiras ainda lança o lodo nos corpos d'água sem tratamento. Por consequência, gera-se um ciclo vicioso e contraditório no qual os rios são os provedores de água 
para as estações de tratamento e também, são receptores dos resíduos gerados pela própria ETA. O investimento em estudos sobre tratamento e reaproveitamento do lodo é necessário para que tal prática de disposição seja evitada, garantindo o gerenciamento dos resíduos de maneira apropriada, sem danos ambientais.

As concessionárias de distribuição de água precisam cumprir disposições legais, tais como: Resolução n. 357 (BRASIL, 2005); NBR 10.004/2004 (ABNT, 2004), o lodo de ETA se enquadra como Resíduo Sólido Classe IIA - Não Inerte; Lei n. 9.605 (BRASIL, 1998); e os padrões de potabilidade da Portaria n. 2.914/2011 (BRASIL, 2011); NBR ISO 14001 (ABNT, 2004), que especifica os requisitos de um Sistema de Gestão Ambiental (SGA); e a várias leis estaduais. Quantificar o volume de lodo gerado é fundamental para acompanhar a rotina da produção e do tratamento do resíduo, e a maioria das estações de tratamento desconsidera a quantidade de lodo gerado. Portanto as ETAs precisam ser vistas como uma indústria geradora de resíduo por cujo tratamento e disposição final são responsáveis.

Mediante os impactos ambientais provocados pelo gerenciamento incorreto do lodo de ETA, pelo volume produzido e com o intuito de analisar a atual situação lodo das ETAs de Mato Grosso do Sul, o presente trabalho abordou a gestão e volume desse resíduo em três estações de tratamento de água a fim de levantar dados, diagnosticar e fazer uma análise crítica com base nas disposições legais de gerenciamento de resíduos para indicar futuras ações - ou melhorias nas ações existentes na região - a partir das dificuldades e oportunidades encontradas no diagnóstico e a busca por soluções para os desafios encontrados na área de estudo.

O objetivo deste trabalho é elaborar o diagnóstico da situação do gerenciamento e volume do lodo de estação de tratamento de água em Mato Grosso do Sul, analisando o sistema de tratamento de água e identificar a etapa na qual o lodo é gerado e os fatores de geração.

\section{METODOLOGIA}

O diagnóstico organizacional basicamente constitui-se em um processo de levantamento de dados e análise das informações sobre um órgão - ou empresa a ser analisado.

A fim de elaborar o diagnóstico da geração de lodo de ETA em Mato Grosso do Sul foram realizadas algumas etapas e instrumentos metodológicos.

Inicialmente, em todas as etapas, foram feitos aprofundados estudos bibliográficos sobre o tema. A revisão compreende a coleta e análise de todos os dados, documentos, instruções, bibliografia especializada (monografias, dissertações, teses, periódicos, revistas técnicas) e legislações disponíveis referentes ao assunto do lodo de ETA. A revisão da literatura abordou sobre uso de diagnóstico organizacional, tratamento da água, mananciais, geração do lodo, sua composição química e propriedades, tratamento, volume gerado, disposição final e reaproveitamento, potencial tóxico e impactos ambientais, maneiras de se destinar corretamente e aspectos legais vigentes.

Essa fase de embasamento teórico estendeu-se ao longo do trabalho e conduziu a pesquisa para as referências necessárias para o entendimento do assunto, análise e conclusões sobre o objetivo do trabalho.

Foram selecionadas três ETAs (ETA A, B e C) no Estado de Mato Grosso do Sul, de diferentes portes, constituindo-se de empresas públicas, privadas ou mistas, cuja tecnologia de tratamento seja convencional de ciclo completo e sendo existente ou não o tratamento do resíduo.

Foram elaborados questionários para obter as informações de projeto e processo e aspectos gerais de cada ETA, assim como sobre a geração do resíduo, produtos químicos utilizados e destinação final do lodo. 
Os questionários foram enviados e entregues entre o período de 22 de junho de 2015 a 29 de setembro de 2015.

As perguntas dos questionários foram elaboradas em linguagem técnica simples, mas sem prejudicar a geração de dados e informações necessárias para o trabalho, tais como: dados gerais, dados de projetos e implantações, mananciais e água bruta, produtos químicos e resíduos e perdas.

Os dados gerais formaram a base para análise e promoveram a caracterização qualitativa e quantitativa de cada ETA. Na tabela 1, encontram-se descritos os principais dados levantados no questionário das três ETAs.

Tabela 1 - Dados levantados no questionário

\begin{tabular}{|c|c|}
\hline Item & Dados \\
\hline Aspectos gerais & $\begin{array}{l}\text { - Tipo de empresa (pública, privada ou mista); } \\
\text { - População abastecida; } \\
\text { - Vazão média anual de operação (l/s); } \\
\text { - Tecnologia de tratamento. }\end{array}$ \\
\hline Projeto e implantação & $\begin{array}{l}\text { - Início de funcionamento da ETA; } \\
\text { - Localização da ETA. }\end{array}$ \\
\hline Manancial e água bruta & $\begin{array}{l}\text { - Lançamento de esgoto a montante de captação; } \\
\text { - Programa de conservação dos mananciais. }\end{array}$ \\
\hline Produtos químicos & $\begin{array}{l}\text { - Coagulante utilizado; } \\
\text { - Produtos adicionais. }\end{array}$ \\
\hline Resíduos e perdas & $\begin{array}{l}\text { - Tipo de água utilizada na limpeza dos decantadores; } \\
\text { - Volume anual de lodo gerado } \\
\text { - Frequência de limpeza dos decantadores; } \\
\text { - Índice de lodo tratado; } \\
\text { - Controle de perdas de água; } \\
\text { - Controle de quantidade de água utilizada nas lavagens dos } \\
\text { filtros e decantadores; } \\
\text { - Controle de volume de lodo gerado nos decantadores. }\end{array}$ \\
\hline
\end{tabular}

\section{RESULTADOS E DISCUSSÕES}

\subsection{Projeto e implantação}

A seguir serão apresentados breves históricos dos projetos e implantação das três ETAs analisadas.

As três ETAS possuem tecnologia convencional de ciclo completo, sendo que uma ETA usa como coagulante o sulfato de alumínio, e as outras duas usam o policloreto de alumínio. Duas ETAs possuem administração privada, e uma possui administração mista. A população abastecida varia entre 12 mil a quase 380 mil habitantes, e a vazão média anual varia entre 485 a 1000 l/s.

$\mathrm{Na}$ Tabela 2, são apresentados os dados gerais referentes ao tipo de administração, vazão média anual, coagulante utilizado e início da operação das três ETAs estudadas. 
Tabela 2 - Dados gerais das três ETAs analisadas

\begin{tabular}{c|c|c|c|c}
\hline ETA & $\begin{array}{c}\text { Tipo de } \\
\text { administração }\end{array}$ & $\begin{array}{c}\text { Vazão média anual } \\
\text { da operação (1/s) }\end{array}$ & Coagulante utilizado & $\begin{array}{c}\text { Início da } \\
\text { operação }\end{array}$ \\
\hline A & Privada & $1000 \mathrm{l} / \mathrm{s}$ & Policloreto de alumínio & 1985 \\
\hline B & Privada & $500 \mathrm{l} / \mathrm{s}$ & Policloreto de alumínio & 1966 \\
\hline C & Mista & $485 \mathrm{l} / \mathrm{s}$ & $\begin{array}{c}\text { Sulfato de alumínio } \\
\text { líquido/granulado }\end{array}$ & 1990 \\
\hline
\end{tabular}

As ETAs A e B possuem administração privada, sendo a ETA A projetada há 31 anos e a ETA B há 50 anos. A ETA C possui administração mista e foi projetada há 26 anos. Entretanto, mesmo após 24 anos de diferença entre a primeira e a última estação projetada, as três ETAs possuem a mesma tecnologia convencional de ciclo completo.

Ressalta-se que as ETAs A e B utilizam o mesmo coagulante em seu processo de tratamento de água e utilizam cloro, flúor e cal hidratada durante o processo. A ETA C utiliza, além do coagulante, cal hidratada para corrigir o $\mathrm{pH}$ da água e polieletrólito como produto auxiliar. As estações de tratamento $B$ e $C$ possuem vazões médias anuais similares - diferença de 151/s, enquanto a estação de tratamento A possui o dobro da vazão da ETA B.

As três ETAs possuem laboratório próprio, sendo a ETA C com laboratórios próprios e conveniados.

As informações e dados levantados no questionário são apresentados em forma de tabelas. Os resultados obtidos futuramente podem ser comparados em uma análise evolutiva (através do tempo) na mesma ETA, e também de forma comparativa entre as diferentes ETAs.

\subsection{Mananciais}

A qualidade e a gestão dos mananciais foram analisadas através de dados quanto a existir lançamento de esgoto neles, haver programas e/ou ações de conservação e possuir a empresa outorga pelo uso da água.

A Tabela 3 apresenta os aspectos gerais de gestão dos mananciais das três ETAs.

Tabela 3 - Controle e gestão dos mananciais que abastecem as ETAs

\begin{tabular}{l|c|c|c}
\hline \multicolumn{1}{c|}{ Aspectos Gerais } & $\begin{array}{c}\text { Mananciais } \\
\text { da ETA A }\end{array}$ & $\begin{array}{c}\text { Mananciais } \\
\text { da ETA B }\end{array}$ & $\begin{array}{c}\text { Mananciais } \\
\text { da ETA C }\end{array}$ \\
\hline $\begin{array}{l}\text { Tem lançamento de esgoto a montante da } \\
\text { captação? }\end{array}$ & Não & Não & Não \\
\hline $\begin{array}{l}\text { Possui programa de conservação de } \\
\text { mananciais? }\end{array}$ & Sim & Sim & Sim \\
\hline Possui outorga pelo uso da água & Sim & Sim & Sim \\
\hline
\end{tabular}

Pela Tabela 3, pode-se observar que todas as ETAs não lançam esgoto a montante de captação e possuem programas de conservação dos mananciais. As três ETAs possuem programas socioambien- tais com a parceria das prefeituras das cidades em que estão localizadas, e as ETAs A e B possuem o certificado ISO 9001:2000 desde 2003 pelo seu Sistema de Gestão de Qualidade. Nas três ETAs, as informações 
sobre os sistemas são compartimentadas, ou seja, cada setor é responsável pelos dados que gera.

O manancial utilizado pela ETA A encontra-se em área de preservação ambiental, sendo utilizado também para a dessedentação de animais, ocasionando a ocorrência de processo de erosão e assoreamento devido ao pisoteamento do gado nas margens do curso d'água. Segundo o decreto municipal da área de proteção ambiental em que o manancial está localizado, proíbe-se o corte da vegetação ao longo das margens do manancial em largura de $200 \mathrm{~m}$.

Informações sobre a qualidade da água bruta nas três ETAs só estão disponíveis após encaminhar uma carta ofício ao setor responsável na empresa em questão e solicitar as análises dos parâmetros da água bruta. Nos sites das ETAs A e B estão disponíveis somente as análises da água potável e, no site da ETA C, não há análises disponíveis.

\subsection{Limpeza do sistema de tratamento}

A Tabela 4 apresenta as informações sobre o controle de perdas de água nas ETAs e, em seguida, informações sobre o tipo de água utilizada na lavagem dos filtros e decantadores.

Tabela 4 - Controle de perdas de água nas ETAs

\begin{tabular}{l|l|l}
\hline ETA & $\begin{array}{l}\text { Possui controle de perdas de } \\
\text { água? }\end{array}$ & $\begin{array}{c}\text { Como é feito o controle de quantidade de água } \\
\text { utilizada nas lavagens dos decantadores? }\end{array}$ \\
\hline A & Sim & Não é feito \\
\hline B & Sim & Não é feito \\
\hline C & DND $^{1}$ & Através de cronometragem nos tempos de lavagens \\
\hline
\end{tabular}

Os resultados da tabela 4 mostram que as ETAs A e B possuem controle de perdas de água durante o processo de tratamento, porém não fazem o controle da quantidade de água que é gasta para lavar os filtros e decantadores; portanto não é possível fazer a comparação entre quantidade de água perdida nas lavagens e água perdida durante o processo de tratamento. Já a ETA C não disponibilizou a informação sobre se possui o controle de perdas de água, porém estima-se a quantidade de água gasta nas lavagens através da cronometragem do tempo gasto para lavar os decantadores e filtros.

Todas as ETAs usam água tratada para lavar os filtros e decantadores após a fase de coagulação e desinfecção, resultando em perdas de água já tratada e dos produtos químicos que foram utilizados durante o processo.

\subsection{Resíduo gerado no decantador}

A seguir estão descritos os dados referentes ao volume de lodo gerado no decantador - estimados por fórmula - e ao gerenciamento dele (Tabela 5).

Tabela 5 - Volume anual de lodo gerado nos decantadores e de tempo de intervalo de limpeza dos decantadores

\begin{tabular}{c|c|c} 
ETA & $\begin{array}{c}\text { Volume anual } \\
\text { de lodo gerado } \\
\mathbf{( k g )}\end{array}$ & $\begin{array}{c}\text { Tempo de intervalo } \\
\text { de limpeza dos } \\
\text { decantadores }\end{array}$ \\
\hline $\mathrm{A}$ & $381.408 \mathrm{~kg}^{1}$ & 3 meses \\
\hline $\mathrm{B}$ & $674.583 \mathrm{~kg}^{1}$ & 3 meses \\
\hline $\mathrm{C}$ & Não é medido & 15 dias \\
\hline
\end{tabular}

Os dados da Tabela 5 mostram que a ETA B, mesmo possuindo vazão média anual menor que a ETA A e abastecendo menos habitantes, gera mais lodo que a ETA A. O principal motivo, segundo 
informações da própria ETA é a poluição e o assoreamento de seus mananciais uma vez que mananciais mais degradados precisam de mais produtos químicos e, logo, geram maior quantidade de resíduo.

Conforme apresentado na Tabela 5 , o tempo de permanência do lodo nos decantadores é de três meses, nas ETAs A e B, e 15 dias, na ETA C. Com o tempo, o lodo acumulado nos tanques tem a sua concentração aumentada, tornando-se mais agressivo ao meio ambiente caso seja disposto in natura. Duas das três ETAs afirmam que o lodo é parcialmente tratado, e uma ETA afirma que o lodo não é tratado o que poderá causar danos ao corpo d'água em que for disposto, e os jatos de água necessários para a limpeza do lodo no decantador não serão suficientes, precisando do uso de raspadores manuais e, logo, o contato direto de funcionários com o resíduo.

Ressalta-se que, independente de haver destinação final, nenhuma ETA possui um sistema de medição ou de dimensionamento da geração dos lodos. As ETAs A e B aplicam métodos teóricos para estimar o volume de lodo gerado.

A Tabela 6 apresenta o dado de eficiência do controle de quantidade de lodo.

Tabela 6 - Dados de eficiência do controle de quantidade de lodo

\begin{tabular}{c|l}
\hline ETA & Eficiência do controle de quantidade de lodo \\
\hline A & $\begin{array}{l}\text { média eficiência do controle da quantidade de lodo gerado nos decantadores, ou } \\
\text { seja, o volume de lodo gerado é estimado por fórmula }\end{array}$ \\
\hline B & $\begin{array}{l}\text { média eficiência do controle da quantidade de lodo gerado nos decantadores, ou } \\
\text { seja, o volume de lodo gerado é estimado por fórmula }\end{array}$ \\
\hline C & $\begin{array}{l}\text { baixa eficiência do controle da quantidade de lodo gerado nos decantadores, ou } \\
\text { seja, o volume de lodo gerado não é medido ou considera-se apenas o volume do } \\
\text { decantador }\end{array}$ \\
\hline
\end{tabular}

Baseado nesses dados, foi diagnosticada a eficiência de controle de quantidade lodo gerado nos decantadores conforme a Tabela 6 . Os resultados foram determinados em razão das condições de medição de quantidade de lodo gerado nos decantadores. As ETAs A e B apresentam média eficiência de controle de quantidade, pois apenas estimam o volume de resíduo por meio de fórmulas. Já a ETA C possui baixa eficiência por não quantificar o lodo gerado.

As ETAs A e B afirmaram no questionário que o volume de lodo gerado é parcialmente tratado, e a ETA C afirmou que o volume gerado não é tratado. Esse dado apresenta, de forma implícita, que, se o lodo não é tratado - ou apenas uma parcela dele é tratada - ele está sendo disposto in natura no meio ambiente, sendo os cursos d'água receptores de lodo passíveis de danos ambientais como assoreamento e deterioração da qualidade da água.

\subsection{Análise crítica dos resultados}

As ETAs analisadas, apesar de não lançarem esgoto a montante e possuírem programas de conservação dos mananciais, ainda não fazem o tratamento total do lodo e também não possuem o controle real da quantidade do resíduo gerado.

Ao analisar os dados referentes à eficiência do controle de quantidade de lodo e se há tratamento de lodo respectivamente, é possível notar que as três ETAs não são ambientalmente corretas em relação ao gerenciamento do lodo. Apenas duas ETAs fazem o tratamento 
parcial do resíduo e estimam o volume com imprecisão. Observou-se que as ações de gerenciamento de resíduo são feitas através de medidas isoladas, como o controle de perdas de água e programa de conservação dos mananciais.

Uma ETA gera mensalmente inúmeros dados e informações sobre seu sistema e cabe aos gestores da estação utilizá-los para que a empresa possa atingir seus objetivos e planejar metas em longo prazo. Obter muitos dados não garante que a empresa os empregue de forma a alcançar um tratamento mais adequado - diminuição de custos preservando a qualidade da água tratada.

Contudo o mais preocupante é a escassez de dados. Caso haja necessidade de algum estudo gerencial, a empresa deverá fazer todo o levantamento de dados para que, após anos, ela possa desenvolver a pesquisa. Logo, o câmbio de informações - que podem trazer melhorias para o sistema - entre instituições de pesquisa e as ETAs deveria ocorrer com mais frequência. Nota-se, até alguns anos atrás, maior interesse na comunidade acadêmica do que nas próprias estações.

Ressalta-se que algumas informações não foram disponibilizadas pelas empresas conforme previsto no questionário. Isso ocorreu em razão de:

- Inexistência de alguns dados;

- Indisponibilidade de acesso;

- Unidade de medida utilizada (padronização);

- Uma única pessoa detentora de informações;

- Informações e dados separados por departamentos;

Para que as ETAs estudadas gerenciem seus resíduos, é preciso que considerem que interferem no meio ambiente, suas atividades são sujeitas a consequências ambientais negativas ou positivas. Cada etapa do processo de tratamento influencia o volume de lodo gerado, portanto é necessário pensar no conjunto de atividades como um todo.

\subsection{Propostas}

A elaboração do diagnóstico permitiu fazer propostas que proporcionem o aproveitamento das informações disponíveis sobre o resíduo das três ETAs, além de abrir o debate a respeito do gerenciamento deste, assim como sua possível minimização e reaproveitamento.

Em relação aos mananciais, sugere-se:

- Fazer o acompanhamento histórico de suas condições de uso e ocupação das margens e áreas de proteção ambiental (zoneamento ambiental);

- A partir dos dados coletados sobre os mananciais e resíduos gerados, implementar um plano de acompanhamento de evolução de cada item analisado no diagnóstico incluindo relatórios mensais de qualidade da água bruta e tratada;

- Através de análises químicas, físicas e biológicas, acompanhar a qualidade da água do manancial;

- Na escolha de futuros mananciais, avaliar a geração de resíduos como fator importante a ser considerado;

- Avaliar as características físico-químicas e mineralógicas do lodo em função da época do ano em que o resíduo é produzido, assim, poderá ser analisada a relação do lodo em função da turbidez e nível do corpo d'água;

- Baseado na legislação existente, estabelecer programas/ações de proteção dos mananciais.

Em relação à destinação e disposição final do resíduo e aspectos gerenciais e operacionais das estações de tratamento:

- Realizar análises e caracterização do lodo para obter maiores informações sobre suas micro e macro propriedades e avaliar seu potencial de utilização e seu potencial poluidor, visto que a 
caracterização do lodo é o primeiro passo para que a escolha do destino e disposição sejam feitos;

- Levantar o quantitativo mensal do lodo gerado em cada ETA, além de seus dados qualitativos;

- Tendo em mãos os dados quantitativos e qualitativos de lodo gerado, compará-lo com o relatório da água bruta utilizada na mesma época;

- Das alternativas de destinação do lodo, a mais viável para as três empresas é investir em estudos, equipamentos e laboratório para desidratar o lodo e, posteriomente, incorporá-lo em materiais cerâmicos, concreto não estrutural, na construção civil, assim como exemplo de outras empresas do setor de tratamento de água;

- Estudar os índices de incorporação do lodo em materiais da construção civil;

- Adquirir os produtos químicos utilizados no processo de tratamento de empresas que sejam certificadas em órgão fiscalizador, pois a qualidade dos produtos utilizados influenciam no volume do lodo gerado (produtos de maior qualidade necessitam de doses menores e logo geram menor quantidade de lodo);

- Utilizar testes e estudos para preparar e melhorar a dosagem dos produtos químicos;

- As empresas precisam ter o controle do volume de água gasto na lavagem dos decantadores e filtros;

- As empresas necessitam investir em estudos da reutilização da água de lavagem no processo de tratamento;

- As empresas devem exigir que seus funcionários usem roupas adequadas durante a lavagem manual dos decantadores para que não tenham contato direto com o lodo;

- Parceria entre as empresas e as intituições de ensino para melhorar e câmbio de informações relativas ao resíduo gerado, pois a qualidade das informações pesquisadas são essenciais para análise da interferência do lodo in natura nos corpos hídricos e na escolha das alternativas para disposição final;

- Analisar as áreas externas de cada ETA para observar a possibilidade de implantação de alternativas de tratamento do lodo;

- À medida que os estudos da aplicação do lodo forem evoluindo, será necessário legislação específica para poder regularizar as novas utilidades do resíduo.

\section{CONSIDERAÇÕES FINAIS}

O diagnóstico realizado para analisar o gerenciamento e volume de lodo gerado em ETAs é fundamental para compreender a situação da gestão do resíduo em diferentes estações do Estado de Mato Grosso do Sul, uma vez que, para planejar, é preciso conhecer os dados disponíveis para, então, definir metas. Através dos dados levantados, podem-se expor as situações a se melhorar, padronizar parâmetros para esses sistemas e discutir sobre a cultura (ou a falta dela) de gestão do lodo das ETAs.

O conhecimento do volume de lodo gerado pelas ETAs e os aspectos legais que os regem são essenciais para se definir estratégias de gerenciamento e/ou disposição final, minimização de geração e escolha de tratamento mais adequado do resíduo. Deve-se abolir a ideia de que o resíduo de ETA é proveniente de materiais retirados dos mananciais e que, por isso, devem ser devolvidos ao manancial.

O trabalho realizado para diagnosticar a situação atual do gerenciamento de lodo gerado nas ETAs de Mato Grosso do Sul possibilita concluir que:

1. Uma ETA gera mensalmente inúmeros dados e informações sobre seu sistema, e cabe aos gestores da estação utilizá-los para que a empresa possa atingir 
seus objetivos e planejar metas em longo prazo. Obter muitos dados não garante que a empresa os empregue de forma a alcançar um tratamento mais adequado - diminuição de custos preservando a qualidade da água tratada. Contudo o mais preocupante é a escassez de dados. Caso haja necessidade de algum estudo gerencial, a empresa deverá fazer todo o levantamento de dados para que, após anos, ela possa desenvolver a pesquisa, portanto a troca de informações com instituições de pesquisa é essencial;

2. Nenhuma das ETAS é compatível com a Lei 12.305/2010 (BRASIL, 2010) em que se deve priorizar a redução, reuso e reciclagem. Sendo o lodo um resíduo - e não um rejeito - ele deveria ter tratamento ecologicamente adequado optando-se por redução, reuso e reciclagem. As três ETAs não podem ser consideradas ecoeficientes na gestão lodo em razão de seus resultados quantitativos, qualitativos e escassez de dados;

3. As ETAs diagnosticadas possuem poucos dados sobre o lodo, inclusive dados históricos, o que dificulta uma melhor discussão sobre o tema e admite a pouca consideração sobre o assunto;

4. Duas ETAs quantificam o lodo gerado apenas por fórmulas estimadas, e uma ETA não sabe a quantidade de lodo produzido. As empresas precisam encarar que o lodo faz parte do processo de tratamento, não se deve ignorar sua geração. $\mathrm{O}$ fato de duas ETAs estimarem o volume de lodo por fórmula e uma ETA não saber o volume de lodo gerado é preocupante, considerando-se que todas as estações estão situadas em municípios com boa estrutura. Tal realidade reflete no trabalho que os gestores das ETAs terão, ao conciliar as leis ambientais com o gerenciamento do lodo para que a prática de gestão desse resíduo seja totalmente realizada;

5. É viável empregar mais de uma opção de destinação e disposição final do lodo em uma mesma ETA. Assim as opções podem se complementares e podem ser aplicadas em diferentes épocas do ano ou ao mesmo tempo, sendo escolhida através da quantidade e característica de lodo gerado. $\mathrm{O}$ aterro sanitário é uma alternativa de disposição final assim como a aplicação em cerâmica vermelha, aplicação no solo e incineração.

\section{REFERÊNCIAS}

ACHON, C. L. Ecoeficiência de sistemas de tratamento de água à luz dos conceitos da ISO 14.001. 2008. 248 p. Tese (Doutorado em Hidráulica e Saneamento) - Universidade de São Paulo (USP), São Carlos, SP, 2008. Disponível em: <http://www.teses.usp.br/ teses/disponiveis/18/18138/tde-08012009172718/pt-br.php>. Acesso em: 19 maio 2015.

ACHON, C. L.; SOARES, L. V.; MEGDA C. R. Impactos ambientais provocados pelo lançamento in natura de lodos provenientes de estações de tratamento de água. In: CONGRESSO BRASILEIRO DE ENGENHARIA SANITÁRIA E AMBIENTAL, 23., Campo Grande, MS, 2005. Anais... Campo Grande: ABES, 2005, cd, I-020, 15 p.

ANDRADE, C. F. et al. Gestão ambiental em saneamento: uma revisão das alternativas para tratamento e disposição do lodo de eta e seus impactos na qualidade das águas. In: CONGRESSO BRASILEIRO DE GESTÃO AMBIENTAL, 5., Belo Horizonte, MG, 2014. Anais... Disponível em: <http://www.ibeas. org.br/congresso/Trabalhos2014/IX-004. pdf>. Acesso em: 15 abr. 2015

ANDREOLI, Cleverson Vitório (Coord.). Resíduos sólidos do saneamento: processamento, reciclagem e disposição final. Rio de Janeiro: RiMa/ABES, 2001. 282 p. Disponível em: <https://www.finep.gov.br/images/apoioe-financiamento/historico-de-programas/ prosab/CLeverson.pdf $>$. 
ASSIS, L. R. Avaliação do impacto em corpos d'água devido ao lançamento de resíduos de uma estação de tratamento de água de Juiz de Fora - MG. 2014. 61 p. Monografia (Graduação em Engenharia Sanitária e Ambiental) Universidade Federal de Juiz de Fora (UFJF), Juiz de Fora, MG, 2014.

ASSOCIAÇÃO BRASILEIRA DE NORMAS TÉCNICAS [ABNT]. NBR-ISO 14001: Sistema de gestão ambiental: especificações e diretrizes para uso. Rio de Janeiro: ABNT, 2004. 14 p.

NBR 10.004: Classificação de resíduos sólidos. Rio de Janeiro: ABNT, 2004. 48 p.

BRASIL. Conselho Nacional de Meio Ambiente (CONAMA). Resolução n. 357 de 17 de março de 2005. Dispõe sobre a classificação dos corpos de água e diretrizes ambientais para o seu enquadramento, bem como estabelece as condições e padrões de lançamento de efluentes, e dá outras providências. Publicado no Diário Oficial da União - DOU n. 053, do dia 18.03.2005, p. 58-63.

Lei n. 9.605 de 12 de fevereiro de 1998. Dispõe sobre as sanções penais e administrativas derivadas de condutas e atividades lesivas ao meio ambiente, e dá outras providências. Publicado no Diário Oficial da União (DOU), Seção 1, do dia 13.02.1998, p. 1.

Lei n. 12.305 de 02 de agosto de 2010. Política Nacional de Resíduos Sólidos. Brasília, DF: Congresso Nacional, 2010.

. Ministério da Saúde. Portaria n. 2.914 de 12 de dezembro de 2011. Dispõe sobre os procedimentos de controle e de vigilância da qualidade da água para consumo humano e seu padrão de potabilidade. Publicado no Diário Oficial da União - DOU, Seção 1, do dia 26 seguinte, p. 266.

COSIN, S.; KOZIEVITCH, V. F. J.; SANTOS, P. S.; VALENZUELA-DÍAZ, F. R. Estudo e caracterização de lodo de estação de tratamento de água visando sua utilização na produção de materiais cerâmicos. In: CONGRESSO BRASILEIRO DE CIÊNCIA E TECNOLOGIA EM RESÍDUOS E DESENVOLVIMENTO SUSTENTÁVEL, Costão do Santinho, Florianópolis, SC, 2004. Anais... Costão do Santinho: ICTR, 2004. 13 p.
HOPPEN, C.; PORTELLA, K. F.; JOUKOSKI, A.; BARON, O.; FRANCK, R.; SALES, A.; ANDREOLI, C.V; PAULON, V. A. Codisposição de lodo centrifugado de Estação de Tratamento de Água (ETA) em matriz de concreto: método alternativo de preservação ambiental. Cerâmica, v. 51, n. 318, p. 85-95, jun. 2005.

INSTITUTO BRASILEIRO DE GEOGRAFIA E ESTATÍSTICA (IBGE). Pesquisa Nacional de Saneamento Básico 2008. Rio de Janeiro, 2010. Disponível em: <http://www.ibge. gov.br/home/estatistica/populacao/ condicaodevida/pnsb2008/PNSB_2008.pdf>. Acesso em: 22 abr. 2015.

KATAYAMA, V. T. Quantificação da produção de lodo de estações de tratamento de água de ciclo completo: uma análise crítica. 2012. 144 p. Dissertação (Mestrado em Engenharia) Escola Politécnica da Universidade de São Paulo (USP), São Paulo, 2014. Disponível em: <http:/ / www.teses.usp.br/teses / disponiveis/3/3147/tde-19072013-161144/ pt-br.php>. Acesso em: 22 maio 2015.

ORGANIZAÇÃO DAS NAÇÕES UNIDAS (ONU). Relatório Mundial das Nações Unidas sobre o Desenvolvimento de Recursos Hídricos - Água para um mundo sustentável. 2015. Disponível em: <http://www.unesco.org/ new/fileadmin/MULTIMEDIA/HQ/SC/ images/WWDR2015ExecutiveSummary_ POR_web.pdf>. Acesso em: 17 mar. 2015.

PORRAS, A. C. Uso de lodo de estação de tratamento de água e agregado reciclado miúdo na fabricação de elementos de alvenaria. 2007. 213 p. Tese (Doutorado em Engenharia Civil) - Universidade Estadual de Campinas (UNICAMP), Campinas, SP, 2007.

RIBEIRO, H. K. S. S. Avaliação de desempenho ambiental em estações de tratamento de água. 2003. 158 p. Dissertação (Mestrado em Tecnologia Ambiental e Recursos Hídricos) - Universidade de Brasília (UnB), Brasília, DF, 2003. Disponível em: <http://livros01. livrosgratis.com.br/cp095826.pdf>.

SILVA, M. V. Desenvolvimento de tijolos com incorporação de cinzas de carvão e lodo provenientes de estação de tratamento de água. 2011. 132 p. Dissertação (Mestrado em Ciências) - IPEN/ Universidade de São Paulo, São Paulo, 2011. 


\section{Sobre os autores:}

Isadora Yule Queiroz de Oliveira: Arquiteta formada em 2010 e Mestranda no Mestrado em Eficiência Energética e Sustentabilidade da UFMS. E-mail: isayule@gmail.com

Odilar Costa Rondon: Professor titular da Universidade Federal de Mato Grosso do Sul. Doutor em Engenharia Civil pela Universidade Federal de Santa Catarina. Mestre em Engenharia Civil pela Universidade Federal Fluminense. E-mail: odilar.rondon@ufms.br 